\title{
QUALIDADE FISIOLÓGICADE SEMENTES DE Ocotea porosa (NEES ET MARTIUS EX. NEES) APÓS DIFERENTES CONDIÇÕES DE ARMAZENAMENTO E SEMEADURA ${ }^{1}$
}

\author{
GLAUCIAALVAREZTONIN² ${ }^{2}$ SONIACRISTINAJULIANAGUALTIERIDEANDRADE PEREZ ${ }^{3}$
}

\begin{abstract}
RESUMO - O teor de água da semente no momento da coleta e o manejo posterior são fatores importantes para a germinação, implicando no sucesso ou fracasso na produção das mudas. Este trabalho teve por objetivo acrescentar informações sobre a viabilidade e o vigor de sementes de Ocotea porosa (imbuia), procurando viabilizar a coleta, o armazenamento e a produção de mudas em viveiro. As sementes com teor de água de 40 e 30\% apresentavam variação na composição química. Estas foram acondicionadas em embalagens (sacos plásticos e vidros) e armazenadas em diferentes ambientes (laboratório e câmara fria) durante seis meses. Depois, foram semeadas em sacos plásticos com diferentes substratos (composto agrícola e solo de cerrado + serragem) e condições de luminosidade (com e sem sombreamento artificial), avaliando-se a porcentagem e velocidade de emergência das plântulas. Realizou-se a análise das variáveis a fim de examinar o tipo de relação entre elas. Identificado uma correlação linear entre as variáveis, procedeu-se à análise de agrupamento (cluster). O uso de sementes coletadas com $40 \%$ de água, armazenadas em laboratório, em sacos plásticos e mantidas sob sombreamento de $65 \%$, em substrato comercial e solo + serragem, produz elevada porcentagem e velocidade de emergência das plântulas. $\mathrm{O}$ acondicionamento em embalagens de vidro prejudica a qualidade fisiológica das sementes durante o armazenamento.
\end{abstract}

Termos para indexação: imbuia, umidade, armazenagem, luminosidade, composição química.

\section{PHYSIOLOGICAL QUALITY OF Ocotea porosa (NESS ET MARTIUS EX NESS) SEEDS AFTER DIFFERENT STORAGEAND SOWINGCONDITIONS}

\begin{abstract}
The seed moisture level at harvest and the following procedures are very important factors for germination, that will results in the success or failure of plant establishment. The aim of this study was to add information about viability and vigour of Ocotea porosa (imbuia) seeds, such as the right time to harvest, the best storage procedure and how to produce plants inside a greehouse. In this study, the seed moisture level was 40 and $30 \%$ and differences in chemical composition were detected. They were stored in plastic bags and glass recipients under ambient conditions in a cool room. The seeds from different conditions were sown in plastic bags containing different substratum (agricultural compound, cerrado soil plus sawdust) maintened under full sunlight and 65\% artificial shading. A combined analysis was carried out to know the relationships between the parameters and to check the type of dependence between them. A linear relationship between the parameters was detected, and thus a cluster analysis was performed. The highest rate and percentage of seedling emergence was registered with seeds presenting $40 \%$ moisture level, stored under ambient conditions, inside plastic bags, sown in agricultural substratum plus cerrado soil and sawdust, maintained under artificial shading. Seed storage in glass recipients decreased seed viability and vigor.
\end{abstract}

Index terms: imbuia, moisture level, storage, luminosity, chemical composition.

\footnotetext{
${ }^{1}$ Submetido em 16/06/2005. Aceito para publicação em 22/03/2006. Parte da Tese de Doutorado da primeira autora apresentada à UFSCar;

${ }^{2}$ Eng. Agrônoma Doutora em Ecologia e Recursos Naturais. Departamento de Botânica, UFSCar. Bolsista CAPES;
}

\footnotetext{
${ }^{3}$ Prof ${ }^{a}$ Adjunta Departamento de Botânica da UFSCar. Via Washington Luiz, Km 235 - Caixa Postal 676, CEP: 13565-905, São Carlos, S.P. dscp@power.ufscar.br
} 


\section{INTRODUÇÃO}

Com o propósito de manter a biodiversidade das matas, para restaurações florestais ou mesmo o plantio para fins paisagísticos e comerciais, há necessidade da coleta de grande número de sementes, uma vez que em muitas espécies, estas apresentam baixa qualidade fisiológica. Todavia, dificuldades relacionadas principalmente com a obtenção das sementes, germinação e produção de mudas têm limitado o aumento da diversidade nos plantios ora realizados (Durigan et al., 2004).

A forma e época de coleta são informações imprescindíveis para a obtenção de sementes com elevada porcentagem de germinação, bom desenvolvimento e manutenção das mudas em campo, pois exige conhecimento da época de maturação, das características de dispersão e das condições climáticas. Assim, a condição fisiológica da semente no momento da coleta é importante para o êxito em sua utilização e manutenção da qualidade.

Em condições de campo, a modificação dos frutos é o melhor indicador para a época da coleta, sendo esta, identificável pela variação de coloração, pela queda natural, por rachaduras ou abertura dos frutos na própria árvore, e pela presença de aves e/ou insetos. A coloração e a deiscência dos frutos foram bons indicadores da maturação de sementes de cedro (Corvello et al., 1999).

As sementes, assim como outras partes da planta, apresentam composição química bastante variável, em função da etapa de desenvolvimento em que elas se encontram ou devido à influência de fatores externos. As variações na constituição química das sementes de diferentes espécies constituem fatores responsáveis pela diferença de longevidade (Carvalho e Nakagawa, 2000).

A deterioração refere-se a toda e qualquer alteração degenerativa e é um processo irreversível, sendo possível, porém, diminuir sua velocidade com o manejo adequado e eficiente das condições ambientais, durante o armazenamento (Baudet, 2003). As condições fundamentais, para o armazenamento das sementes da maioria das espécies, são a umidade relativa do ar e a temperatura do ambiente de armazenamento, pois tanto um como outro influem diretamente nas taxas metabólicas das sementes. Além destes fatores, pode-se incluir ainda o grau de umidade da semente durante o armazenamento e os tipos de embalagens utilizados (Carneiro e Aguiar, 1993).

As embalagens utilizadas no armazenamento devem ajudar a diminuir a velocidade do processo de deterioração, mantendo o grau de umidade inicial das sementes armazenadas, com o intuito de diminuir a respiração. Nodari et al. (1998) ressaltam uma relação positiva entre o tipo de embalagem e a manutenção da qualidade das sementes de palmiteiro (Euterpe edulis). No entanto, Santos (2003) não encontrou diferenças significativas quanto ao uso de diferentes tipos de embalagens no armazenamento de sementes de branquilho (Sebastiana commersoniana).

Com relação à germinação e emergência das plântulas, 0 substrato é um dos fatores externos que influencia tanto a germinação das sementes quanto o desenvolvimento das mudas. Para as espécies florestais nativas existem poucas recomendações quanto aos tipos de substratos a serem utilizados, porém têm sido pesquisados o carvão, esfagno, fibra de coco e, principalmente, vermiculita (Figliolia et al., 1993). Para a produção de mudas o importante é que o substrato apresente boa drenagem, alta capacidade de retenção de nutrientes, seja leve, de baixo custo e de fácil manuseio, sendo que, os materiais mais utilizados são: solo arenoso, palha de arroz carbonizada, casca de pinus ou eucalipto triturada, turfa, palha de café (Santarelli, 2001).

Um outro fator importante na emergência e no crescimento das mudas é a luminosidade, devido à influência em processos como a fotossíntese. Fatores como a intensidade, qualidade, duração e periodicidade da luz incidente afetam quantitativa e qualitativamente o desenvolvimento da planta (Pedroso e Varela, 1995).

Pertence a família Lauraceae (Carvalho, 2003), Ocotea porosa (Nees et Martius ex. Nees), segundo Lorenzi (1992), é conhecida em todo o Brasil com os nomes de imbuia, embuia, canela-imbuia, imbuia-clara, imbuia-preta, umbuia, imbuiazebrina e que apresenta como sinonímia botânica os nomes de Phoebe porosa (Nees e Mart.) Mez e Cinnamomum porosum (Nees e Mart.) Kost. Trata-se de uma espécie nativa com distribuição em matas temperadas do sul do Brasil, que atinge cerca de $30 \mathrm{~m}$ de altura quando adulta. A semente é uma castanha, com superfície lisa, contendo numerosas estrias e pode medir de 12 a $20 \mathrm{~mm}$ de diâmetro. A madeira de seu tronco é utilizada para marcenaria de mobiliário de luxo, para a construção civil, como planta ornamental, e tem potencial para uso em perfumaria pois, através de destilação, extrai-se um fixador, considerado superior ao extrato de sândalo (Carvalho, 2003).

Este trabalho teve como objetivo estudar a viabilidade e o vigor de sementes de Ocotea porosa, que possuiam diferentes teores de água.e foram armazenadas em diferentes condições, antes da semeadura em dois substratos, sob duas intensidades luminosas. 


\section{MATERIAL E MÉTODOS}

O trabalho foi conduzido no Laboratório de Ecofisiologia de Sementes e no Jardim Experimental do Departamento de Botânica, ambos no "Campus" da Universidade Federal de São Carlos, em São Carlos- SP. Foram utilizadas sementes retiradas de frutos maduros, os quais apresentavam uma coloração violácea escura a preta, de Ocotea porosa (Nees et Martius ex. Nees) coletados na Divisão de Florestas e Estação Experimental do Instituto Florestal - DFEE, em Itararé - SP. O experimento teve início em abril de 2001 com a coleta e transporte dos frutos, acondicionados em sacos de polietileno.

Os frutos foram despolpados em água corrente, friccionados sobre peneira de malha grossa para a remoção do epicarpo e do mesocarpo, servindo também como escarificação mecânica para as sementes. Essas foram colocadas sobre peneira de malha grossa para secar superficialmente, em ambiente de laboratório, durante 24 horas. Foi realizada uma seleção manual das sementes, descartando-se as danificadas e deformadas. Para a obtenção de uniformidade de tamanho utilizaram-se sementes que tinham entre 12 e $15 \mathrm{~mm}$ de diâmetro. Estas sementes passaram por uma assepsia utilizando-se hipoclorito de sódio a $4 \%$, durante dois minutos, em seguida, foram lavadas em água corrente, e em solução de Captan (5\%) durante cinco minutos. Em seqüência foram colocadas para secar sobre folhas de papel toalha antes de serem armazenadas.

$\mathrm{O}$ teor de água foi determinado com o uso de duas repetições de 50 sementes intactas (método direto), conforme descrito em Brasil (1992), expressando-se os resultados em porcentagem do peso úmido. $\mathrm{O}$ teor de água inicial foi de $40 \%$. Parte dessas sementes foram armazenadas com este teor de água e a outra parte foi seca, em ambiente de laboratório, até atingir 30\% de água, para depois serem estocadas. Decorrido o período de seis meses de armazenamento, foi determinado novamente o teor de água destas sementes.

Os teores de carboidratos totais (amido), lipídios totais e proteína foram determinados no Laboratório de Tecnologia de Produtos Agropecuários do Departamento de Tecnologia da FCAV/UNESP, Campus de Jaboticabal-SP. Os teores de lipídio e proteína foram determinados pelo método prescrito pela A.O.A.C. (1990). Para determinação dos carboidratos, expresso como amido, foi determinado o teor de glicose, conforme descrito por Miller (1959).

$\mathrm{O}$ acondicionamento das sementes foi feito em vidros de conserva com capacidade de $550 \mathrm{~mL}$, esterilizados por calor seco, através de estufa, e fechados utilizando-se fita de vedação hidráulica (politetrafluoretileno - PTFE) e fita adesiva sobre a tampa de plástico, ficando estes completamente cheios. Foram utilizados também sacos de polietileno de $25 \times 30 \mathrm{~cm}$, com $0,1 \mathrm{~mm}$ de espessura. Foram utilizadas embalagens impermeáveis e semi-permeáveis como alternativas e com o propósito de minimizar a perda de umidade pelas sementes, principalmente em ambientes com baixa temperatura. As sementes foram armazenadas durante seis meses em ambiente de laboratório (com temperatura média de $25^{\circ} \mathrm{C}$ e UR do ar em torno de $70 \%$ ) e em câmara fria (Temperatura de $9^{\circ} \mathrm{C} \pm 2^{\circ} \mathrm{C}$ e UR do ar de 50\%), pertencente ao Departamento de Produção Vegetal da FCAV/UNESP de Jaboticabal - SP.

Foi realizado um teste preliminar de emergência antes do armazenamento das sementes, em areia grossa lavada e esterelizada (Brasil, 1992), onde as sementes apresentaram $91 \%$ de emergência. O teste de emergência, após o armazenamento, foi realizado semeando-se as sementes diretamente em sacos pretos de polietileno, com $14 \mathrm{~cm}$ de largura por $27 \mathrm{~cm}$ de altura, com volume aproximado de $4 \mathrm{~L}$, preenchidos com: serragem + solo de cerrado (retirado à profundidade de 20 a $30 \mathrm{~cm}$ ) na proporção de 2:1 (mistura curtida durante quatro meses, com $\mathrm{pH} 5,7$ ) e substrato agrícola, recomendado para mudas de espécies florestais (com pH 5,8 e composto de material orgânico de origem vegetal, vermiculita expandida e nutrientes).

Para cada substrato foram utilizadas quatro repetições com vinte sementes, semeadas entre três e quatro centímetros de profundidade (Hartmann e Kester, 1983). Os recepientes, contendo substratos e sementes, foram irrigados quando necessário, e as plantas daninhas eliminadas manualmente. $\mathrm{O}$ teste foi conduzido a pleno sol e a $65 \%$ de sombreamento (obtido com a utilização de tela de poliolefinas de cor preta, dentro de estufa com ventilação forçada, modelo Double Poly $\mathrm{Pad} / \mathrm{Fan})$.

Avaliou-se a emergência em campo, onde os dados obtidos na contagem de plântulas foram utilizados para calcular a porcentagem e velocidade de plântulas emergidas para cada repetição e o resultado expresso como a média aritmética das quatro repetições. As contagens foram realizadas diariamente a partir do dia em que a primeira plântula emergiu do substrato. Ao final de 270 dias, os dados diários foram empregados na fórmula de velocidade de emergência, segundo metodologia descrita por Labouriau (1983). Considerou-se como plântulas emergidas aquelas que apresentavam o epicótilo com no mínimo meio centímetro sobre a superfície do substrato.

$\mathrm{O}$ delineamento experimental foi o inteiramente 
casualizado com quatro repetições (recipientes plásticos) e vinte sementes por repetição, num esquema fatorial $2^{5}$ representados pelo teor de água, tipo de embalagem, ambiente de armazenamento, intensidade de luz e tipo de substrato.

Realizou-se uma análise das variáveis de interesse, tendo identificado uma correlação linear entre as variáveis, procedeuse com uma análise de agrupamentos (clusters), que consiste na segmentação das 32 configurações em um número reduzido de grupos, permitindo, a partir dos grupos formados, extrair conclusões relevantes acerca do experimento realizado. Utilizou-se para a análise o programa Statistica 6.0 e Minitab 10 for Windows.

\section{RESULTADOS E DISCUSSÃO}

Os resultados obtidos para o teor de água após o período de armazenamento são apresentados na Tabela 1. Observa-se que as embalagens de plástico e de vidro, consideradas semipermeável e impermeável respectivamente, mantiveram praticamente inalterado o grau inicial de umidade, não diferindo pelo teste $\mathrm{F}$, em nível de $5 \%$ de probabilidade. No entanto, observa-se que sementes acondicionadas com teor de água de $30 \%$ em embalagem de vidro, mantiveram mais elevada a umidade do que as sementes acondicionadas em embalagem de plástico e armazenadas em ambiente de laboratório.

Devido ao interesse em duas variáveis de resposta (porcentagem e velocidade de emergência das plântulas), verificou-se a independência entre elas. Esta informação pode ser avaliada através da construção de um gráfico de dispersão. A Figura 1 apresenta o gráfico de dispersão, onde os pontos expressam a porcentagem e velocidade de emergência, enquanto que a Tabela 2 apresenta a codificação atribuída a cada uma das configurações. Pode-se verificar através da

TABELA 1. Valores médios do teor de água das sementes de imbuia (Ocotea porosa) após seis meses de armazenamento, com teor de água inicial de $40 \%$ e $30 \%$.

\begin{tabular}{|c|c|c|c|c|}
\hline & \multicolumn{4}{|c|}{ Teor de Água (\%) } \\
\hline & \multicolumn{2}{|c|}{40} & \multicolumn{2}{|c|}{30} \\
\hline Ambiente & Vidro & Plástico & Vidro & Plástico \\
\hline Câmara Fria & $40,2 \mathrm{~ns}$ & $42,0 \mathrm{~ns}$ & $34,5 \mathrm{Aa}$ & $32,0 \mathrm{Aa}$ \\
\hline Laboratório & $40,1 \mathrm{~ns}$ & $36,9 \mathrm{~ns}$ & $39,5 \mathrm{Aa}$ & $21,0 \mathrm{Ba}$ \\
\hline
\end{tabular}

ns - Médias não diferem entre si pelo teste $\mathrm{F}$ a $5 \%$ de probabilidade.

Médias seguidas pela mesma letra, maiúscula na linha e minúscula na coluna, não diferem ao nível de $5 \%$ de probabilidade pelo teste de Tukey.

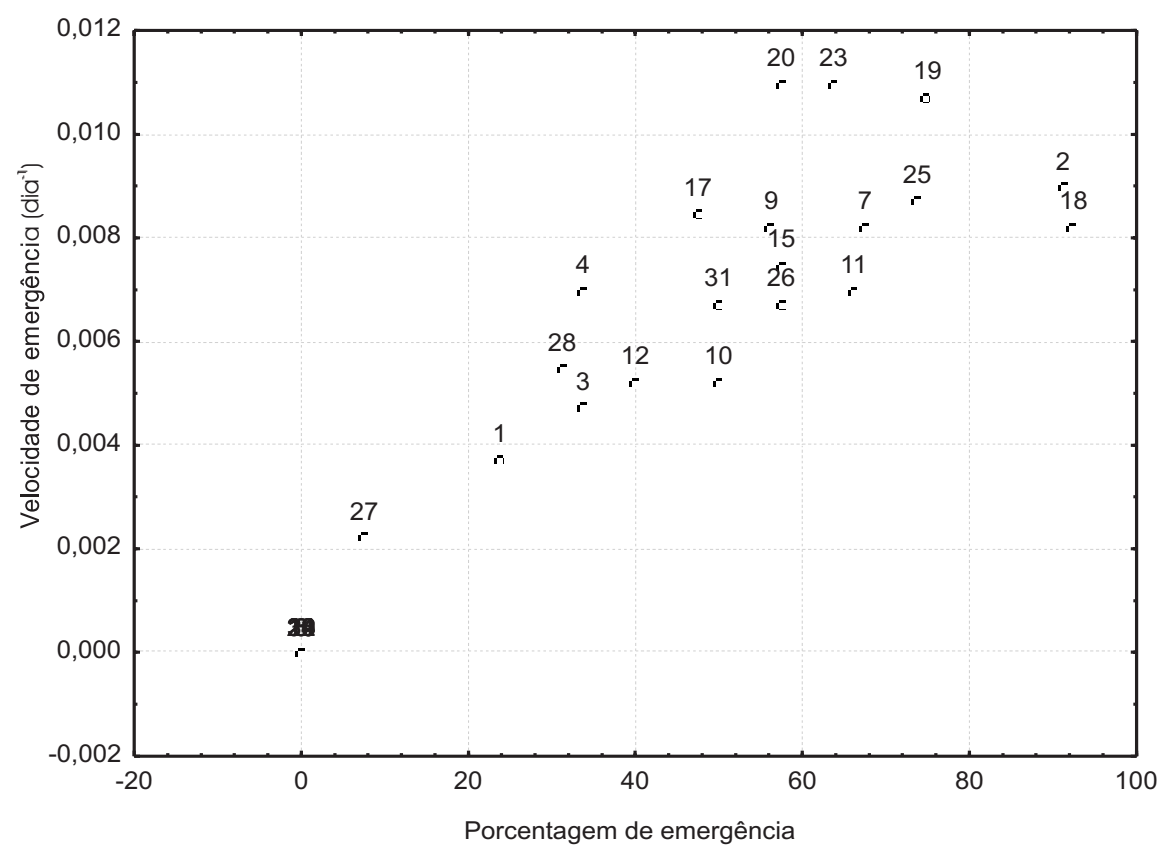

FIGURA 1. Gráfico de dispersão de velocidade e porcentagem de emergência de plântulas de Ocotea porosa, armazenadas em diferentes condições, durante seis meses. Os números contidos no gráfico representam as configurações contidas na Tabela 2. 
Figura 1 uma correlação linear entre as duas variáveis, o que torna conveniente a utilização de técnicas multivariadas na análise em questão.

A análise de agrupamentos (cluster) consiste em agrupar observações (no caso, configurações), que apresentam maior similaridade quanto às respostas produzidas (Johnson e Wichern, 1998), neste caso, porcentagem e velocidade de emergência.

Um método gráfico utilizado em análise de clusters é o dendograma, que apresenta os agrupamentos realizados por ordem do problema em estudo. As retas verticais indicam os grupos que estão sendo formados, enquanto seus comprimentos indicam quão similares são os grupos formados. Quanto maior a reta que une grupos ou observações, menos similares são as observações unidas (Figura 2).

Optou-se por considerar a formação de cinco grupos, o que corresponde aos grupos formados pelo índice de similaridade igual a 88,40 . As várias configurações presentes à direita no dendograma, aparentemente, não se agrupam entre si, o que não é verdade. O que de fato ocorreu é que estas configurações não apresentaram emergência em nenhuma das quatro réplicas, observaram-se valores iguais a zero para as duas variáveis resposta (Figura 2).

A partir do dendograma apresentado, com o auxílio do gráfico de dispersão da Figura 1, tornou-se possível identificar

TABELA 2. Valores médios de porcentagem e velocidade de emergência $\left(\right.$ dia $^{-1}$ ) para cada uma das configurações analisadas

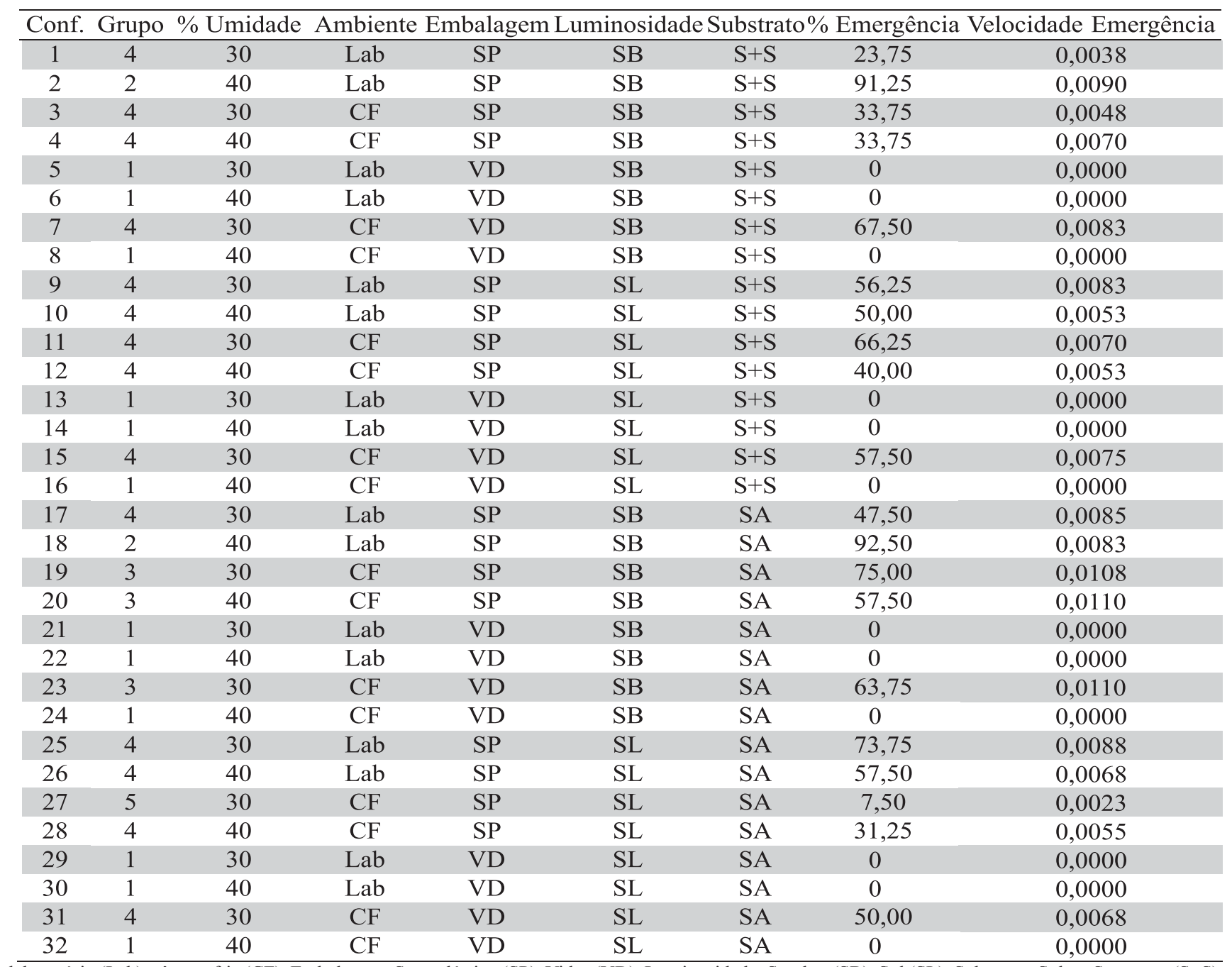

laboratório (Lab), câmara fria (CF), Embalagem: Saco plástico (SP), Vidro (VD). Luminosidade: Sombra (SB), Sol (SL). Substrato: Solo + Serragem (S+S), Substrato Agrícola (SA). 


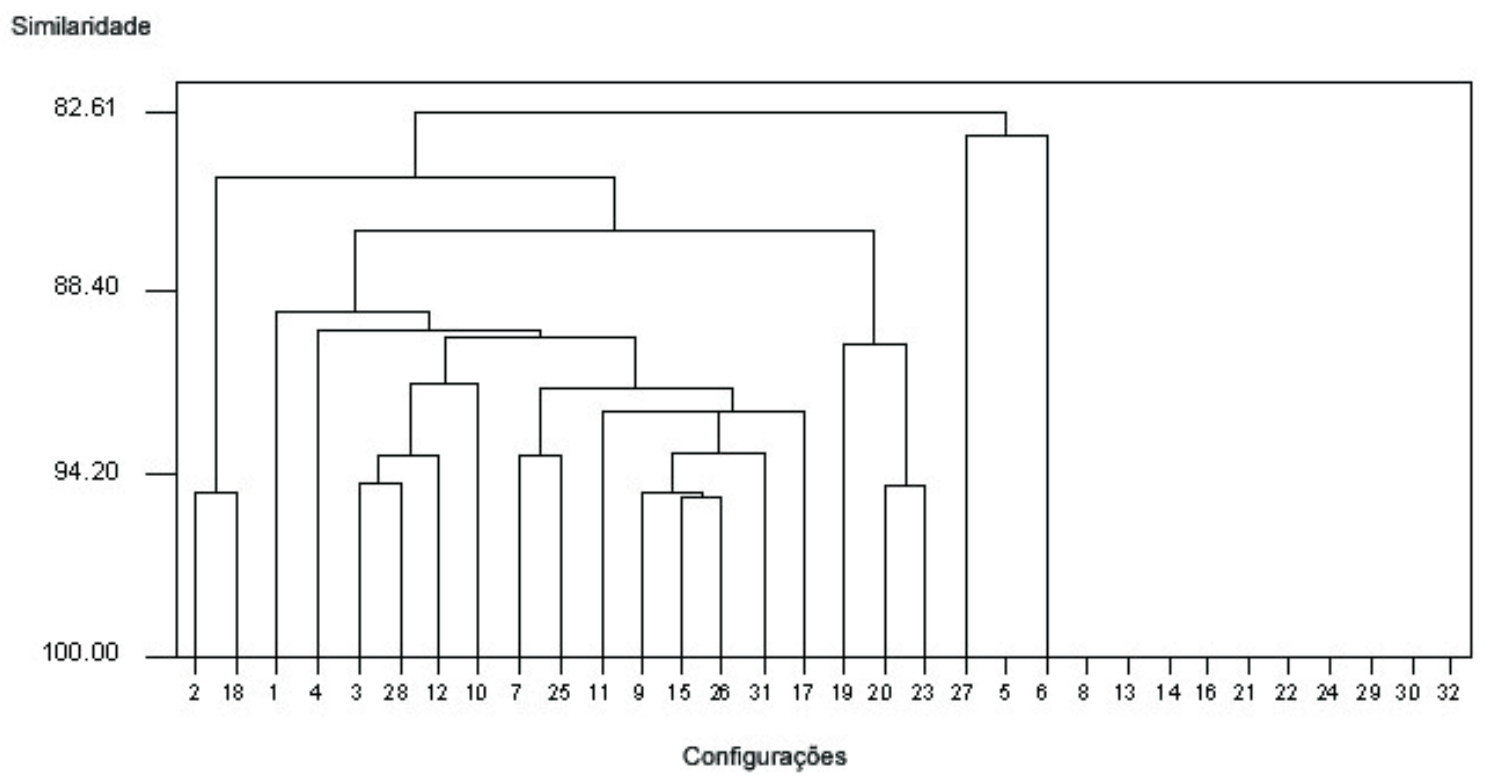

e caracterizar os grupos de acordo com as configurações agrupadas. A Tabela 2 apresenta os códigos para cada grupo formado. O primeiro grupo é formado por todas as configurações em que as plântulas não emergiram, não apresentando, conseqüentemente, porcentagem nem velocidade de emergência. Pode-se observar que dentre as configurações listadas, há sementes armazenadas com os dois teores de água, em dois ambientes de armazenamento, duas intensidades luminosas e substratos diferentes. Todas estas variações aparecem mais de uma vez no grupo 1. O fator embalagem, no entanto, é o vidro, para as 12 configurações pertencentes a este grupo $(5,6,8,13,14,16,21,22,24,29$, 30 e 32), o que fornece indícios de que as embalagens de vidro, neste caso, são responsáveis pela inibição da emergência.

Com relação às embalagens de vidro, há que se considerar que em embalagens impermeáveis não ocorrendo trocas gasosas entre as sementes e a atmosfera e, com elevados teores de água, a respiração das sementes ocorre em altas taxas e o bloqueio destas trocas pode causar a morte das sementes (Neves, 1994). Além disso, durante o armazenamento as sementes liberam compostos voláteis, que são prejudiciais e desta forma o acondicionamento hermético poderia causar o acúmulo destes compostos, acelerando a deterioração das sementes (Zhang et al., 1993).

As reações peroxidativas em lipídios são as maiores causas de deteriorações das sementes durante o armazenamento. Esta reação de peroxidação tem início com a geração espontânea de radicais livres através de autooxidação ou é catalisada por enzimas oxidativas (Ferguson et al., 1990). Estes radicais podem produzir danos em membranas e continuar a propagar outros radicais livres que terminam em reações degenerativas (McDonald, 1999).

Outra observação importante refere-se ao fato de que as quatro únicas configurações $(7,15,23$ e 31$)$ correspondentes às sementes acondicionadas em embalagens de vidro, e que houve emergência de plântulas, apresentaram em comum a combinação de $30 \%$ de umidade, com armazenamento em câmara fria. Segundo Wilson e McDonald (1986), quando o conteúdo de água das sementes é diminuído, a autoxidação é mais comum e é acelerada por altas temperaturas e aumento na concentração de oxigênio. Neste caso, embora as sementes de imbuia apresentassem um teor menor de água, estas pemaneceram armazenadas sob baixas temperaturas.

Além disso, pela análise química realizada detectou-se que estas sementes apresentaram quantidades de amido proporcionalmente maiores que lipídios e proteínas (Tabela 3). As sementes ricas em proteínas absorvem mais água do que as ricas em lipídios e amido (Harrington, 1972), o que leva a se considerar que a composição química de sementes de imbuia favorece sua longevidade quando acondicionadas em sacos plásticos. 
TABELA 3. Composição química (g.100g-1) de sementes de imbuia (Ocotea porosa) com teor de água de 40 e $30 \%$.

\begin{tabular}{cccc}
\hline Teor de Agua (\%) & Lipídios totais & Proteína & Carboidratos \\
\hline 40 & $17,66(0,53)$ & $3,38(0,32)$ & $21,20(0,44)$ \\
30 & $21,11(0,48)$ & $5,30(0,34)$ & $26,47(0,33)$ \\
\hline
\end{tabular}

Obs:Os números entre parênteses indicam o desvio padrão.

As configurações do grupo 2 (2 e 18) se destacaram pela elevada porcentagem de emergência, sendo as únicas que superaram o patamar de $80 \%$. Além disso, apresentaram elevadas velocidades de emergência, ainda que não fossem as maiores. $\mathrm{O}$ que caracterizou este grupo foi o fato das duas configurações serem praticamente idênticas, a não ser pelo tipo de substrato. A combinação de $40 \%$ de umidade com armazenamento em laboratório, embalagem em saco plástico e pouca luminosidade, devido ao sombreamento artificial, foi responsável por uma elevada porcentagem e velocidade de emergência, tanto para o tipo de substrato de menor custo como para o composto de serragem curtida, que pode ser produzido em pequenos viveiros, como para substrato agrícola comercial, onde existem nutrientes químicos, porém de maior custo.

O grupo 3 destacou-se por apresentar as configurações (19, 20 e 23) com maiores velocidades de emergência, sendo as únicas a ultrapassaram $0,010 \mathrm{dia}^{-1}$. Além disso, apresentaram porcentagem de emergência entre 57 e $75 \%$. A combinação responsável por esta resposta foi composta pelo armazenamento em câmara fria, emergência em $65 \%$ de sombreamento e em substrato agrícola, uma vez que os demais fatores apresentaram variações entre as três configurações pertencentes a este grupo. Deve-se ressaltar, entretanto, o fato de que a quarta configuração incluiu esta combinação (configuração 24), onde não houve emergência. Isto pode ser decorrente da interação desta combinação com a embalagem de vidro, que como visto anteriormente, foi um fator que impediu a emergência.

As configurações que compuseram o grupo 4 foram bastante heterogêneas, e responsáveis por velocidades de emergência intermediárias, não merecendo maior destaque. O grupo 5 foi formado por apenas uma configuração. Isto se deveu ao fato de que dentre as configurações em que as sementes apresentaram emergência, esta se destacou pelos baixos índices de porcentagem e velocidade de emergência apresentados.

\section{CONCLUSÕES}

Há interferência do teor de água inicial das sementes, das condições de armazenamento, do substrato e luminosidade na emergência e no vigor de plântulas e mudas de imbua, 270 dias após a semeadura.

Elevadas porcentagens e velocidades de emergência são obtidas utilizando-se sementes coletadas com teor de água de $40 \%$, acondicionadas em saco plástico, armazenadas em laboratório ou câmara fria, semeadas em substrato agrícola e mantidas sob sombreamento de $65 \%$.

Embalagens de vidro não são recomendadas para o armazenamento de sementes de imbuia.

\section{REFERÊNCIAS}

BAUDET, L. Armazenamento de Sementes. In: PESKE, S.T.; ROSENTHAL, M.D.; ROTA, G.M. (Ed). Sementes: fundamentos científicos e tecnológicos. Pelotas: Gráfica Universitária-UFPel, 2003. p.369-418.

BOAS, O.; DURIGAN, G. Pesquisas em conservação e recuperação ambiental no oeste paulista. São Paulo: Páginas \& Letras. 2004. p.199-239.

BRASIL. Ministério da Agricultura e Reforma Agrária. Regras para análise de sementes. Brasília:SNDA/DNDV/CLAV, 1992.365p.

CARNEIRO, J.G.A.; AGUIAR, I.B. Armazenamento de sementes. In: AGUIAR, I.B.; PIÑA-RODRIGUES, F.C.M.; FIGLIOLIA, M.B. (Coord.). Sementes florestais tropicais. Brasília: ABRATES, 1993. p. 333-350.

CARVAlho, N.M.; NAKAGAWA, J. Sementes: ciência, tecnologia e produção. 4 ed. Jaboticabal: FUNEP, 2000. 588p.

CARVALHO, P.E.R. Espécies arbóreas brasileira. Colombo, PR. EMBRAPA FLORESTAS, 2003. v.1. 1039p.

CORVELLO, W.B.V.; VILLELA, F.A.; NEDEL, J.L.; PESKE, S.T. Maturação fisiológica em sementes de cedro (Cedrela fissilis Vell.). Revista Brasileira de Sementes, Brasília, v.21, n.2, p.23-27, 1999.

FERGUSON, J.M.; TEKRONY, D.M.; EGLI, D.M. Changes during early soybean seed and axes deterioration: II. Lipids. Crop Science, Madison, v.30, p.179-182, 1990.

FIGLIOLIA, M.B.; OLIVEIRA, E.C.; PIÑA-RODRIGUES, F.C.M. Análise de sementes. In: AGUIAR, I.B.; PIÑA-RODRIGUES, F.C.M.; FIGLIOLIA, M.B. (Coord.). Sementes florestais tropicais. Brasília: ABRATES, 1993. p.137-174.

HARRINGTON, J.F. Seed storage and longevity. In: KOZLOWSKI,T.T. (Ed.) Seed biology. New York: Academic Press, 1972. v.2. p.145-245.

HARTMANN, H.T.; KESTER, D.E. Plant propagation: principles and practices. 4 ed. New Jersey: Prentice-Hall, 1983. 727p. 
JOOHNSON, R.A.; WICHERN, D.W. Applied multivariate statistical analisys. 4 ed. Upper Saddle River: Prentice Hall, 1998. $816 \mathrm{p}$.

LABOURIAU, L.G. A germinação das sementes. Washington, D.C. OEA. 1983. 175p.

LORENZI, H. Árvores Brasileiras: manual de identificação e cultivo de plantas arbóreas do Brasil. Nova Odessa: Plantarum, $1992.368 \mathrm{p}$.

McDONALD, M.B. Seed deterioration: physiology, repair and assessment. Seed Science and Technology, Zürich, v.27, p.177237, 1999 .

MILLER, G.L. Use of dinitrosalicylic acid reagent for determination of reducing sugars. Analytical Chemistry, London, v.31, n.3, p.426$428,1959$.

NEVES, C.S.V.J. Sementes recalcitrantes: revisão de literatura. Pesquisa Agropecuária Brasileira, Brasília, v.29, n.9, p.1459-1467, 1994.

NODARI, R.O.; FANTINI, A.C.; GUERRA, M.P.; REIS, M.S.; SCHUCH, O. Conservação de frutos e sementes de palmiteiro (Euterpe edulis Martius) sob diferentes condições de armazenamento. Revista Árvore, Viçosa, v.22, n.1, p.1-10, 1998.
OFFICIAL METHODS OF ANALYSIS OF THE ASSOCIATION OF OFFICIAL ANALYTICAL CHEMISTS. Offifical Methods of Analysis. 15ed. Virginia: OAOC, v.2, 1990. 1298p.

PEDROSO, S.G.; VARELA, V.P. Efeito do sombreamento no crescimento de mudas de sumauma (Ceiba pentandra (L.) Gaertn). Revista Brasileira de Sementes, Brasília, v.17, n.1, p.47-51, 1995.

SANTARELLI, E.G. Produção de mudas de espécies nativas para florestas ciliares. In: RODRIGUES, R.R.; FILHO, H.F.L. (Ed.) Matas Ciliares: conservação e recuperação. 2 ed. São Paulo: Editora da Universidade de São Paulo: FAPESP, 2001. p.313-317.

SANTOS, S.R.G. Potencial de armazenamento e qualidade fisiológica de sementes de Sebastiana commersoniana (Bail.) Smith \& Downs. 2003. 89f. Tese (Doutorado em Agronomia Produção Vegetal) - Faculdade de Ciência Agrárias e Veterinárias, Universidade Estadual Paulista, Jaboticabal, 2003.

WILSON, D.O.; McDONALD, M.B. The lipid peroxidation model of deterioration. Seed Science and Technology, Zürich, v.14, p.269300, 1986.

ZHANG, M.; LUI, Y.; TORII, I.; SASAKI, H.; ESASHI, Y. Evolution of volatile compounds by seeds during storage periods. Seed Science and Technology, Zürich, v.21, p.359-373, 1993.

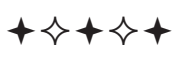

